\title{
Zapatismo y autonomía entre las comunidades indígenas en Chiapas
}

\author{
José Alejos García
}

Bruno Baronnet, Mariana Mora Bayo

Y RichARD STAHLER-SHOLK (COORDS.), 2011

Luchas "muy otras". Zapatismo y autonomía en las comunidades indígenas de Chiapas

Universidad Autónoma Metropolitana-Xochimilco, Centro de Investigaciones y Estudios Superiores en Antropología

Social, Universidad Autónoma de Chiapas, México, 577 pp.

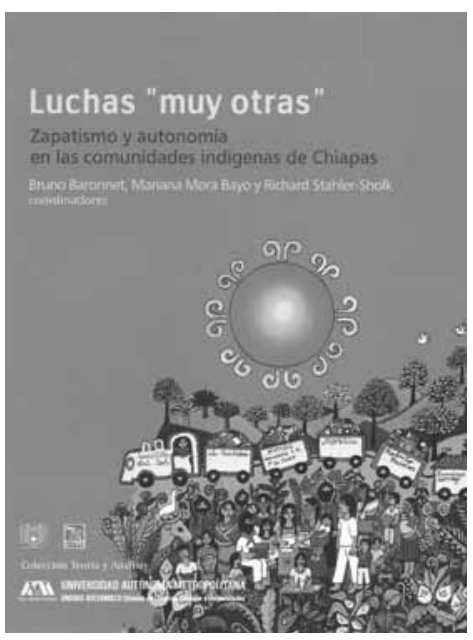

$L$ uchas "muy otras"... es una contribución colectiva de especial interés para la discusión antropológica y el estudio del actual movimiento zapatista, un libro lleno de ideas teóricas novedosas y de un optimismo y una solidaridad evidentes. Destaca una reflexión crítica sobre el quehacer de las ciencias sociales, en específico de la investigación etnográfica, pero también respecto de las posturas epistemológicas, ideológicas y

\section{Zapatism and Autonomy among the Indigenous Communities in Chiapas}

José Alejos García: Instituto de Investigaciones Filológicas, Universidad Nacional Autónoma de México, Distrito Federal, México jalejosg@hotmail.com

Desacatos, núm. 45, mayo-agosto 2014, pp. 163-166 políticas, muchas veces ocultas, investigación científico-social. En tal sentido, se aprecia la declaración explícita de algunos autores acerca de sus posicionamientos, principalmente éticos e ideológico-políticos, resumidos en su empatía y compromisos con el zapatismo. Se postula que la investigación debe ser una actividad orientada claramente hacia el beneficio de los sujetos de estudio. El volumen reúne artículos de discusión teórica de interés para la antropología y para otras ciencias sociales, como el artículo de Speed sobre el neoliberalismo, el derecho y la autonomía, o el de Harvey, que abunda sobre el paso 
del imperialismo al imperio del capital y plantea al zapatismo como "otra forma de política" y su ejercicio de autonomía como una "alternativa económica y política” (p. 173).

Otras contribuciones combinan planteamientos teóricos con experiencias etnográficas en comunidades zapatistas. El concepto de "autonomía" es el que genera mayor interés, como queda expuesto en el ensayo de Cerda García, una revisión crítica del concepto de "ciudadanía" en el contexto de la lucha zapatista por la autonomía. Otros escritos de orientación etnográfica, como los de Baronnet, Gutiérrez Narváez y Núñez Patiño, describen la lucha de las comunidades

\section{zapatistas por lograr una}

educación autónoma, con métodos educativos más congruentes con la sociedad y la cultura de los educandos, con el objetivo de romper con la subordinación y alienación contenidos en los programas oficiales. El mismo tenor se encuentra en el estudio de Forbis sobre el proyecto zapatista de salud y en el de Rico Montoya acerca de los efectos de la llamada "guerra de baja intensidad" en los niños y la implementación de una pedagogía de la resistencia. El texto de Santiago Vera examina la estrategia de la "guerra integral de desgaste", al tiempo que propone una crítica a la psicología hegemónica y subraya la participación y capacidad organizativa de la mujer zapatista, entre los principales temas. En general, el libro tiene la virtud de no ser una mera compilación de documentos generados de manera individual, sino de ser "un ejercicio de auto-reflexión crítico colectivo", como se indica en el prólogo y en las conclusiones.

El volumen se compone de cinco capítulos y 15 artículos, que van desde los cuestionamientos teórico-metodológicos de la investigación antropológica hasta temas concretos de ciudadanía e identidad, educación, salud, economía y recursos naturales, examinados concretamente en poblados zapatistas de Chiapas. Según se indica, las investigaciones iniciaron en 2003 y concluyeron en 2007 con la realización de un taller de discusión que contó con otros participantes, además de los autores del libro. Hay una dedicatoria a Andrés Aubry, fallecido en aquel año y quien fuera uno de los promotores de esta publicación, historiador y decidido luchador social, acompañante del movimiento zapatista, cuya orientación crítica es compartida por los colaboradores.

En cierto sentido podríamos equiparar esta orientación crítica del libro, bien representada en el artículo de Aubry, con la postura zapatista de "abajo y a la izquierda", señalada por Harvey (p. 164), lo cual significa que el investigador asume un posicionamiento junto a las comunidades zapatistas en su lucha de emancipación frente al "mal gobierno" y el neoliberalismo. Como apuntan los autores de la introducción, el libro busca, mediante un análisis de las prácticas políticas de autonomía zapatistas y del impacto del movimiento, avanzar hacia una "reconceptualización de lo político", una reflexión "pluriversal", contrahegemónica y antisistémica. Dos ejes centrales, aportados por las mismas bases de apoyo zapatistas, organizan el libro: la autonomía como base de nuevas prácticas del poder y de la democracia, y la producción de nuevas identidades políticas (p. 21). A ello se agregan tres inquietudes principales - origen de la compilación-: la necesidad política de análisis y reflexión como una contribución al movimiento zapatista, el interés por acercar a este último a las luchas sociales de otros países, sobre todo latinoamericanos, y el interés por el papel de la investigación en la lucha social (pp. 35-37).

Los autores del libro son académicos destacados, especialistas en los temas tratados y en general comparten la postura de que la investigación antropológica debe abandonar la idea de una supuesta "objetividad científica”, que se traduce en imparcialidad y distancia, para reconocer las subjetividades involucradas y convertirse en una "investigación-acción", 
"comprometida", "situada". La actividad de la investigación debe ser conocida, aprobada y contar con la participación de la población estudiada. Los conocimientos así obtenidos deben estar orientados a resolver problemas sociales y reportar beneficio directo para la comunidad. Esto se evidencia en el esfuerzo de algunos autores por explicitar su posición ideológicopolítica a favor del zapatismo y contra el gobierno y el neoliberalismo, así como en la crítica a la investigación "colonialista", que extrae información de las poblaciones estudiadas para propósitos personales, como la obtención de un grado académico, la publicación de un libro o conseguir un empleo en una institución académica, si no es que para otros propósitos ocultos, como los de proveer conocimientos estratégicos al gobierno y organizaciones nefastas.

Esta postura se ejemplifica en el artículo de Aubry, quien critica duramente a las ciencias sociales por despreciar el "gran saber colectivo de la comunidad estudiada", por la "incapacidad del investigador para producir un instrumento - otro que no sean sus escritos-como devolución de su trabajo, susceptible de inspirar una práctica transformadora", y por los candados de las instituciones académicas, del Sistema Nacional de Investigadores y del Consejo
Nacional de Ciencia y Tecnología

(pp. 59-60). Cuestiona

igualmente la pretendida

"neutralidad académica" y

considera que "nuestra ciencia

social, en demasiados casos, es una miseria intelectual y moral, inhumana y sin ética" (p. 61), a lo que contrapone una investigaciónacción, comprometida, orientada a la resolución de problemas concretos de la sociedad estudiada. En el plano etnográfico, esta postura se expone en el estudio de Núñez Patiño sobre la educación en una escuela zapatista chol, en el que se critica el modelo de educación bilingüe bicultural y el concepto de "interculturalidad" de la escuela oficial. La autora propone la socialización de la educación como un modelo alternativo y menciona que su "participación como activista [...] proporcionó la confianza de la gente para desarrollar la investigación, acordando apoyar a los promotores en las clases como una forma de retribución" (p. 282).

En general, es notable la aproximación metodológica de los trabajos etnográficos por la participación y decisión activa de las comunidades de estudio, los temas investigados, los objetivos y los procedimientos de obtención de información, como muestra el artículo de Mora Bayo (p. 87 y ss.), quien describe el procedimiento "dialógico" de su investigación. También Speed retoma el concepto dialógico de
Bajtín (p. 137) como marco para entender la redefinición zapatista de "derecho" y "autonomía", en términos de la dinámica entre lo global y lo local. Así, un rasgo de las colaboraciones del volumen es su perspectiva colaborativa y dialógica, evidente en la asociación entre el investigador y la población estudiada, en el esfuerzo por hacer explícito el compromiso directo de éste con los problemas y temas de interés de la población, y en la intención de rescatar las voces locales y las perspectivas de los sujetos sociales, que incluye la perspectiva del propio investigador.

Me parece relevante aludir al estudio de Aquino Moreschi, dedicado al problema de la migración de indígenas zapatistas otros textos, en los que se destacan las bondades de la vida autónoma en contraste con las perversiones de la sociedad circundante, su estudio se acerca a un tema difícil para el zapatismo: la precariedad económica al interior de la comunidad y el creciente fenómeno migratorio entre sus integrantes. Sobresale también la divergencia respecto de la metodología empleada, pues en vez de limitarse a un recuento de entrevistas o a la organización y participación en talleres, asume una postura propiamente etnográfica, se sitúa en el punto de vista de un personaje y sigue 
su trayectoria de vida. Se trata de un documento que permite plantear interrogantes sobre aspectos no visibles en los otros trabajos, como las condiciones de vida reales en las comunidades autónomas, las perspectivas laborales para sus habitantes, los conflictos agrarios y el consumo clandestino de alcohol, entre otros.

A continuación presento algunos comentarios críticos. Uno de los aspectos más interesantes del libro es su crítica a la investigación científico-social y su propuesta de una investigación situada y comprometida. Me parece una llamada de atención pertinente, pues muchos esfuerzos y recursos invertidos en investigación están orientados por modas intelectuales y no tienen como finalidad un beneficio para la población investigada. Sin embargo, establecer una división radical entre la investigación comprometida $-\mathrm{y}$ por tanto éticamente correcta- y la no comprometida $-\mathrm{y}$ por tanto incorrecta y "miserable" - es un acto maniqueo, que dista mucho de representar una actitud propiamente científica. Es muy arriesgado juzgar el compromiso de un investigador a partir de un beneficio inmediato, directo o tangible, ya que hay muchas maneras de entender y asumir un compromiso y distintos medios para aportar beneficios. Los investigadores formados como intelectuales tienen un lugar desde donde aportar, $y$ en tal sentido sus escritos no deben ser despreciados.

Otro aspecto relevante de la obra es la crítica a la "objetividad" en la ciencia social. Creo que poner en evidencia la subjetividad que interviene en la investigación no debe llevarnos a sustituir una por la otra. Por el contrario, hacer explícitos estos factores subjetivos es un acto de objetividad, que permite comprender y analizar en perspectiva los resultados de la investigación de que se trate. De esta manera, es posible aquilatar el peso que la militancia, el compromiso y las restricciones declaradas por el investigador puedan ejercer en el contenido de sus escritos. Es notable la falta de referencias a estudios etnográficos relacionados con los temas de los artículos del libro. En general, se privilegia la entrevista, con poco ejercicio analítico, y se muestra poca profundidad en los asuntos culturales, lo cual podría atribuirse a la fuerte dosis de teoría y a la escasa observación etnográfica. Por último, considero un aporte importante la discusión teórica de conceptos como "política", "derecho" y "autonomía", inspirados en las prácticas del movimiento zapatista. En efecto, los zapatistas han desarrollado una comunidad autónoma en un contexto de enormes carencias, de cerco, acoso y falta de alternativas, sin olvidar la participación del apoyo "solidario" de agencias internacionales, pero pretender que ese tipo de comunidad pueda ser una alternativa "campesina" viable frente al neoliberalismo y al imperio del capital, como se sugiere en la introducción (p. 50), en Harvey (pp. 172-173) y en Stahler-Sholk (pp. 430-444), me parece un exceso de euforia y un desborde de la utopía. 